\title{
Lionel Sharples Penrose (1898-1972)
}

\author{
$M A, M D, D S c$, FRCP, FRS
}

The death of Lionel Penrose is a particularly great loss to human genetics in Britain, for most of the workers here of any standing in the discipline owe much to his teaching and encouragement and many of them have been stimulated by his example, help, and ready advice. His influence has also been great-

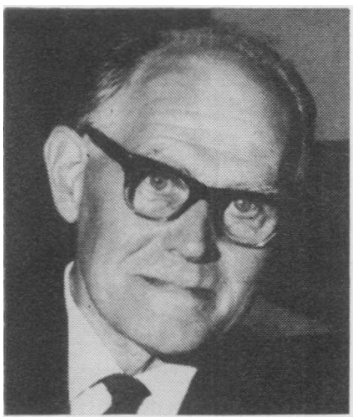

ly spread by his writings and we were most fortunate in having him on the Editorial Committee of this Journal right from the beginning. $\mathrm{He}$ brought with him the wide knowledge and great experience gained from his Editorship of the much older Annals of Human Genetics.

Born in London on 11 June 1898, the son of James Doyle Penrose, artist, and elder brother of Sir Roland Penrose, artist and critic, Lionel Sharples Penrose was educated at The Downs Preparatory School, Colwall, Leighton Park School, Reading, and St John's College, Cambridge. His education was interrupted by a period of service with the Friends Ambulance Unit in France in 1918. At Cambridge he obtained a first-class degree in moral sciences. Turning to medicine he did a year's postgraduate study in the psychological department at Vienna University before entering St Thomas's Hospital for his clinical studies. He qualified with the Conjoint Diploma in 1928 and proceeded to his MD in 1930.

He spent only a few months as assistant in the pathological laboratory at St Thomas's before going as a research student to Cardiff City Mental Hospital. He then spent 9 years (1931-39) as Research Medical Officer at the Royal Eastern Counties Institution, Colchester, where in cooperation with the MRC he did research into the causes of mental defect, the results of which were the subject of an MRC special report (No. 229, Clinical and Genetic Study of 1,280 Cases of Mental Defect, 1938). From 1939 to 1945 he was Director of Psychiatric Research in Ontario, where he was attached to the provincial department of health, was physician to the Ontario Hospital, and lecturer in psychiatry at the University of Western Ontario, besides being medical statistician to the province. He returned to England in 1945 to become Galton Professor of Eugenics at University College London. When he retired in 1965 he was made Emeritus Professor, and became Director of the Kennedy-Galton Centre, Harperbury Hospital, St Albans where he did exceptional work until his death.

His major work was in human genetics and, starting from his work on phenylketonuria in the early thirties, he developed and communicated an enthusiasm for what came to be called human biochemical genetics. With R. A. Fisher, his predecessor in the Galton chair, he also pioneered the study of genetic linkage in man-a growing field which dates directly from his effective launching push. His interests were wide ranging. $\mathrm{He}$ did important research on schizophrenia and designed non-verbal tests of intelligence still in current use. Many of his interests in biology, for instance fingerprints, demography, and cytogenetics, stemmed from his preoccupation with the problem of mental defect. $\mathrm{He}$ made especially important contributions to our understanding of mongolism some of which he communicated at the time of the presentation of the Joseph P. Kennedy, $\mathrm{Jr}$, Foundation award in 1963. This was but one of many honours and distinctions that he gained-Buckstone Browne Medal in 1933, the Weldon Medal for Biometrics in 1950, FRS in 1953, and FRCP in 1962, besides honorary doctorates conferred by McGill University and the University of Newcastle. He also gained the first annual award in 1965 by the Leon Bernard Foundation for research into mental subnormality.

In spite of Professor Penrose's scientific achievements, many people will remember him best on account of his interesting personality. There was something magnetic in his deep set eyes and wide grin and a most attractive feature, as David Garnett wrote in The Times, was his amusing shyness in presenting his own ideas, though it did not hide his enthusiasm. Garnett thought that the prime motive of his mind was intellectual amusement and that the reason he was such an original scientist was because he had an instinct for playing with ideas, as a kitten plays with cotton reels. This made him extremely good company, though his Quaker background made him something of a puritan in that he distrusted show and extravagance. He had a delightful sense of the ridiculous as well as a keenly analytical and sceptical mind. For example, he refused to believe in the association between blood group $O$ and duodenal ulcer until he had persuaded me to investigate the problem in families rather than use the general population as a control.

Lionel and his wife, the most hospitable of people, were ever ready to entertain in their country house near Colchester. He never ceased to admire and sometimes to paint the subtleties of that peaceful landscape. Beside painting he was a chess player of no mean ability, and displayed his creative gift as a composer of chess problems. His love of the game was shared by his family and his youngest son, Jonathan, was the longest reigning British chess champion.

He regarded war as a wasteful and damaging form of human activity and believed that it presented an analogy with disease. Later on, however, he came to realize that whereas the removal of disease requires no substitution, yet the abolition of war does so in order to fulfil some profound impulse in the human race. With the help of some like-minded colleagues, including Sir Alexander Haddow, he founded the Medical Association for the Prevention of War in 1952.

Professor Penrose married in 1928 Margaret, daughter of John Beresford Leathes, FRCP, FRS. They had three sons and one daughter.

C. A. Clarke 